\title{
Adjuvant bisphosphonate use in patients with early stage breast cancer: a physician survey
}

\author{
Sharon McGee ${ }^{1,2} \cdot$ Mashari Alzahrani $^{1} \cdot$ Lisa Vandermeer $^{2} \cdot$ Katherine Cole $^{1} \cdot$ Gail Larocque $^{3} \cdot$ Arif Awan $^{1,2}$. \\ Brian Hutton ${ }^{4} \cdot$ Gregory Pond $^{5} \cdot$ Deanna Saunders $^{2} \cdot$ Mark Clemons $^{1,2}$ (1)
}

Received: 15 December 2020 / Accepted: 12 February 2021 / Published online: 23 March 2021

(c) The Author(s), under exclusive licence to Springer Science+Business Media, LLC, part of Springer Nature 2021

\begin{abstract}
Purpose Despite the increasing use of adjuvant bone-modifying agents (BMAs) such as zoledronate and clodronate in the treatment of patients with early stage breast cancer (EBC), little is known about real world practice patterns. A physician survey was performed to address this deficit and determine interest in clinical trials of alternative strategies for BMA administration.

Methods Canadian oncologists treating patients with EBC were surveyed via an anonymized online survey. The survey collected information on: physician demographics, knowledge and interpretation of adjuvant bisphosphonate guidelines, and real world prescribing practices. Questions also determined thoughts around the design of future adjuvant BMA trials. Results Of 127 surveyed physicians, 53 eligible invitees responded (response rate 42\%). The majority of physicians are offering high-risk postmenopausal patients adjuvant BMAs. The most common BMA regimen was adjuvant zoledronate $(45 / 53,85 \%)$ every 6 months for 3 years. Concerns around toxicities and repeated visits to the cancer centre were perceived as the greatest barriers to adjuvant bisphosphonate use. Respondents were interested in future trials of de-escalation of BMAs comparing a single infusion of zoledronate vs. 6-monthly zoledronate for 3 years. The most favoured primary endpoints for such a trial included disease recurrence and fragility fracture rates.

Conclusion Questions around optimal use of adjuvant bisphosphonates in patients with EBC still exist. There is interest among physicians in performing trials of de-escalation of these agents. The results of this survey will assist in designing pragmatic clinical trials to address this question.
\end{abstract}

Keywords Adjuvant bisphosphonates $\cdot$ Zoledronate $\cdot$ De-escalation $\cdot$ Survey

Mark Clemons

mclemons@toh.ca

1 Department of Medicine, Division of Medical Oncology, The Ottawa Hospital and the University of Ottawa, 501 Smyth Road, Ottawa, Canada

2 Cancer Therapeutics Program, Ottawa Hospital Research, and University of Ottawa, Ottawa, Canada

3 The Ottawa Hospital Cancer Program, The Ottawa Hospital, Ottawa, Canada

4 Clinical Epidemiology Program, The Ottawa Hospital Research Institute and University of Ottawa, Ottawa, Canada

5 Department of Oncology, Juravinski Cancer Centre and McMaster University, Hamilton, Canada

\section{Introduction}

Patients with early stage breast cancer (EBC) are at an increased risk of skeletal morbidity, reflected through fragility fractures, and an increased risk of developing bone metastases. The results of trials evaluating bonemodifying agents such as bisphosphonates and the results of a subsequent meta-analysis demonstrated that in postmenopausal women, or premenopausal patients receiving ovarian suppression, adjuvant bisphosphonates reduced the rate of distant breast cancer recurrence, recurrence in the bone, and improved breast cancer survival [1]. Ultimately, national and international evidence-based treatment guidelines have recommended that bisphosphonates (usually zoledronate or clodronate) be considered as adjuvant therapy for postmenopausal patients with higher risk breast cancer who are deemed candidates for adjuvant 
systemic therapy [1, 2]. Another recent guideline has recommended that adjuvant bisphosphonates be part of treatment for postmenopausal patients (naturally or induced), who are treated with chemotherapy, and/or have a greater than 12\% 10-year risk of breast cancer death [3].

Despite these guidelines, the uptake of these recommendations has been variable. At the 2019 St Gallen Consensus Conference, only $42.6 \%$ of the international panel reported routine use of BMAs in patients with EBC [4], despite the previous conference "strongly endorsing" their use to improve disease outcomes in post-menopausal women with breast cancer [5]. Similarly, data obtained from Cancer Care Ontario (14/April/2020, personal communication Fatuma for the Data Disclosure Team, CCO) shows that only about $20 \%$ of eligible breast cancer patients in Ontario are receiving adjuvant bisphosphonate therapy [6].

Given the variable clinical uptake of these agents, a survey targeting physicians treating patients with $\mathrm{EBC}$ was conducted to identify knowledge and interpretation of adjuvant bisphosphonate treatment guidelines, and current bisphosphonate prescribing practices. In addition, as the CCOASCO Practice Guideline, 'Bottom line recommendations' states, "More research is recommended comparing different bone-modifying agents, doses, dosing intervals, and durations" [2], we asked physicians what future adjuvant BMA trials they felt would be worth performing. The information obtained from the survey will be used to learn more about real world practice, explore unanswered questions and assist in the design of clinical trials to address these questions.

\section{Materials and methods}

\section{Study population}

Health care providers (medical oncologists, surgical oncologists, oncology nurse practitioners) involved in the systemic treatment of patients with EBC, across all Canadian provinces, were the target population.

\section{Study outcomes}

The information sought in the survey aimed to obtain insights on real world adjuvant BMA prescribing practices, such as the proportion of health care providers who were prescribing these agents, and how they identified suitable patients for these therapies. In addition, we wished to determine health care provider interest in the design of future adjuvant BMA studies and seek feedback as to which endpoints are most relevant for such studies.

\section{Survey development}

The survey was designed by a multidisciplinary team with established expertise in survey development and performance. The survey was pilot tested on two oncologists (MC, SMG) before launch. The first section of the survey was devised to collect basic demographic information (e.g. profession [medical oncologist, surgical oncologist etc.], duration in practice). The second section aimed to determine physician knowledge of current clinical practice guidelines on the use of adjuvant BMAs (e.g. guidance available, eligible patients, treatment benefits). The third section was designed to clarify physician interpretation and application of clinical guidelines (e.g. definitions of eligible patients), and real-world prescribing patterns (e.g. percentage of patients offered treatment, patient characteristics [i.e. menopausal status, chemotherapy use], agent/ schedule used). The final section explored physician ideas for the design of future trials of BMA use, including preferred endpoints, agents, and dosing schedule.

\section{Survey implementation}

Potential participants were contacted using a collection of publicly available email addresses accessible to the investigators that has been used in previous surveys of this type [7]. This includes members of the Canadian Association of Medical Oncologists. The oncology nurse practitioners were contacted through the Canadian Association of Oncology Nurses (CANO) website. The online survey was run using Microsoft Forms from the research coordinator's secure account within the Ottawa Hospital Research Institute. Physicians were sent an invitation to complete the survey, a link to the electronic survey, and a study information sheet. Another reminder notice was sent to participants two weeks later. The survey was approved by the Ontario Cancer Research Ethics Board (OCREB). After the survey had started, we received approval to add a question asking physicians specifically what 10-year mortality rate they would use to consider adjuvant BMA treatment for. This was based on the ESMO guideline that recommended adjuvant bisphosphonate use for patients treated with chemotherapy, and/or have a greater than $12 \%$ 10 -year risk of breast cancer death $[3,8]$.

\section{Data analysis}

All data was summarized descriptively. The frequency of each answer choice was tabulated as a proportion of the 
total number of respondents for that category. Data were analyzed using Excel.

\section{Results}

\section{Physician demographics}

Between October 19 and November 13, 2020, the electronic survey was sent out to 146 physicians; 19 invitees were not eligible (maternity leave, no longer treating breast cancer, retired, out of office or e-mail address invalid). A total of 52 eligible invitees responded for a physician response rate of $41 \%$ (52/127). Unfortunately, the response rate could not be calculated for the nurse practitioners, as the CANO website sent the survey to all oncology nurses in Canada with no information on the number who are either nurse practitioners or who treat breast cancer. Of the total eligible respondents $(n=53)$, the majority were medical oncologists $(47,88.7 \%$ ) (Table 1). Respondents spanned a broad range of clinical practice experience, including $28.3 \%$ with less than 5 years and $15.1 \%$ with over 20 years in independent practice.

\section{Health care provider awareness of practice guidelines}

All 53 respondents were aware of at least one clinical practice guideline recommending the use of adjuvant bisphosphonate therapy in patients with EBC. With respect to the individual guideline groups the most common were for; Cancer Care Ontario and American society of Clinical Oncology (ASCO-CCO) (49/53, 94.2\%), European society for Medical Oncology ESMO (22/53, 42.3\%), and St Gallen $(14 / 53,26.9 \%)$. From these different sources, physicians were aware that guidelines recommended adjuvant bisphosphonate therapy be considered either for "patients with natural or treatment induced menopause, and high-risk disease" $(34 / 53,64.2 \%)$ or "EBC with natural or treatment induced menopause" (13/53, 24.5\%).

With respect to the populations who benefit from adjuvant bisphosphonate therapy reported in the EBCTCG metaanalyses, the most common responses were for; reduced risk of disease recurrence/relapse in the bone $(48 / 53,90.6 \%)$, increased breast cancer specific survival $(30 / 53,56.6 \%)$ and increased overall survival $(23 / 53,43.4 \%)$. When physicians were asked about patient populations who benefited from adjuvant bisphosphonate in EBCTCG study, 35/53 (67.3\%) mentioned only postmenopausal patients benefited and $15 / 52(28.2 \%)$ mentioned that only postmenopausal patients with high risk disease benefited.

\section{Physician personal practice with respect to adjuvant bisphosphonates}

The majority of respondents $(41 / 53,77.4 \%)$ recommend adjuvant BMAs for patients with natural or treatment induced menopause, and high-risk disease. Only two respondents did not recommend adjuvant bisphosphonates (Table 2). When asked to define what they felt would be considered high risk features, the most common answers were; node positive disease $(47 / 53,88.7 \%)$, patients who received chemotherapy $(47 / 53,88.7 \%)$ and patients with high Oncotype DX scores (39/53, 73.6\%) (Table 2).

When asked for recurrence risk thresholds to recommend adjuvant bisphosphonate use $>12 \%, 25 / 53(47.2 \%)$ of respondents would consider a 10-year disease recurrence risk $>10 \%$ for adjuvant bisphosphonate use. After we had received responses from 17 respondents, the survey was modified. A question asking physicians specifically what 10-year mortality rate they would use to consider adjuvant BMA treatment, and for 35 respondents was added and the most common answer was $>5 \%(17 / 35,48.6 \%)$.

The majority of physicians felt that the benefit from adjuvant bisphosphonates was seen in patients with all receptor types $(23 / 53,43.4 \%)$ or mainly in ER/PR positive cohorts $(25 / 53,47.2 \%)$. In their practice oncologists offer adjuvant bisphosphonate therapy to patients they consider high risk either "Always" $(14 / 53,26.4 \%)$, or "Frequently (> 75\% of the time)" (27/53, 50.9\%). Adjuvant zoledronate (47/53, $88.7 \%$ ) was the most commonly used BMA at a schedule of either; every 6 months for 3 years $(45 / 53,84.9 \%)$ or 6-monthly for 5 years $(4 / 53,7.5 \%)$. No physicians were prescribing clodronate. The greatest barriers to the wider use of adjuvant bisphosphonate therapy were; risk of toxicities on treatment (e.g. renal toxicity, ONJ, atypical fractures) $(34 / 53,64.2 \%)$ and the requirement for prolonged follow up, at the cancer centre $(28 / 53,52.8 \%)$. Only $5(9.4 \%)$ respondents felt the breast cancer benefits of adjuvant bisphosphonates were not clinically meaningful.

\section{Potential future trials of adjuvant BMAs}

Respondents were asked for their views on future trials of adjuvant BMAs with respect to trials evaluating deescalation of treatment. Most (45/53, 84.9\%) would enroll patients on de-escalation trials (Table 3). If such a trial was performed, primary endpoints identified as most important were: a "Combination of the incidence of bone metastasis recurrence as well as the incidence of fragility fractures" (14/53, 26.4\%); a "Combination of the incidence of breast cancer recurrence at any site including loco-regional as well as the incidence of fragility fractures" $(14 / 53,26.4 \%)$; or the "Incidence of breast cancer recurrence at any site including loco-regional" $(9 / 53,17.0 \%)$. The most important secondary 
Table 1 Physician Demographics and awareness of practice guidelines

\begin{tabular}{|c|c|c|}
\hline & $N$ & $N(\%)$ \\
\hline Profession & 53 & \\
\hline Medical oncologist & & $47(88.7 \%)$ \\
\hline Surgical oncologist & & $3(5.7 \%)$ \\
\hline General ppractitioner in oncology & & $0(0 \%)$ \\
\hline Nurse practitioner in oncology & & $1(1.8 \%)$ \\
\hline Other, please specify & & $2(3.8 \%)$ \\
\hline General internist doing medical oncology & & 1 \\
\hline Physician assistant & & 1 \\
\hline Time in independent practice & 53 & \\
\hline Less than 5 years & & $15(28.3 \%)$ \\
\hline $5-10$ years & & $15(28.3 \%)$ \\
\hline $10-15$ years & & $5(9.4 \%)$ \\
\hline $15-20$ years & & $10(18.9 \%)$ \\
\hline More than 20 years & & $8(15.1 \%)$ \\
\hline Awareness of different adjuvant bisphosphonate practice guidelines, (multiple selections possible) & 52 & \\
\hline ESMO & & $22(42.3 \%)$ \\
\hline $\mathrm{ASCO} / \mathrm{CCO}$ & & $49(94.2 \%)$ \\
\hline St Gallen & & $14(26.9 \%)$ \\
\hline Other, please specify & & $3(5.8 \%)$ \\
\hline Alberta Cancer Care Guidelines & & 1 \\
\hline $\mathrm{NCCN}$ & & 1 \\
\hline Alberta Health Services & & 1 \\
\hline Patient groups that guidelines recommend adjuvant bisphosphonates be considered: & 53 & \\
\hline All patients with early stage breast cancer & & $3(5.7 \%)$ \\
\hline All patients with early stage breast cancer with high risk disease & & $2(3.8 \%)$ \\
\hline $\begin{array}{l}\text { All patients with early stage breast cancerwith natural or treatment induced menopause (i.e. through ovarian sup- } \\
\text { pression) }\end{array}$ & & $13(24.5 \%)$ \\
\hline All patients with natural or treatment induced menopause, and high-risk disease & & $34(64.2 \%)$ \\
\hline Other & & $1(1.8 \%)$ \\
\hline Benefits of adjuvant bisphosphonates highlighted in EBCTCG meta-analysis, (multiple selections possible) & 53 & \\
\hline Reduced risk of disease recurrence/relapse in bone & & \\
\hline Reduced risk of disease recurrence/relapse in other non-bone sites & & $48(90.6 \%)$ \\
\hline Increased overall survival & & $11(20.7 \%)$ \\
\hline Increased breast cancer specific survival & & $23(43.4 \%)$ \\
\hline Reduction in fragility fractures & & $30(56.6 \%)$ \\
\hline Populations EBCTCG meta-analysis reported benefit & 52 & \\
\hline All patients benefited & & $1(1.9 \%)$ \\
\hline Only post-menopausal patients benefited & & $35(67.3 \%)$ \\
\hline Only post-menopausal patients with high risk disease benefited & & $15(28.8 \%)$ \\
\hline Other, please specify: & & $1(1.9 \%)$ \\
\hline Only post-menopausal ER+ patients benefited & & 1 \\
\hline
\end{tabular}

EBCTCG Early Breast Cancer Trialists Collaborative Group

endpoints were overall survival $(12 / 53,22.6 \%)$, toxicities $(7 / 53,13.2 \%)$ and the incidence of metastatic bone recurrence $(7 / 53,13.2 \%)$.

When presented with a choice of different scenarios of clinical trials, or the option to cite their own alternative design, the majority ranked a randomised trial comparing a single infusion of zoledronate vs. zoledronate every 6 months for 3 years $(44 / 53,83.0 \%)$ as their top choice (Table 3). Alternative trial designs suggested by survey recipients are shown in Supplementary Appendix 1. 
Table 2 Physician personal practice with respect to adjuvant bisphosphonate use

\begin{tabular}{|c|c|c|}
\hline & $N$ & $N(\%)$ \\
\hline In which patients do you recommend adjuvant bisphosphonate therapy & 53 & \\
\hline I don't recommend these agents & & $1(1.9 \%)$ \\
\hline All patients with natural or treatment induced menopause & & $7(13.2 \%)$ \\
\hline All early stage breast cancer patients, regardless of menopausal status & & $0(0 \%)$ \\
\hline Patients with natural or treatment induced menopause, and high-risk disease & & $41(77.4 \%)$ \\
\hline Patients with high risk disease, regardless of menopausal status & & $1(1.9 \%)$ \\
\hline Other, please specify & & $3(5.6 \%)$ \\
\hline Definition of high risk disease, requiring adjuvant bisphosphonate treatment, (multiple selections possible) & 53 & \\
\hline Patients with primary tumour $>\mathrm{T} 2$ & & $22(41.5 \%)$ \\
\hline Patients with primary tumour $>\mathrm{T} 3$ & & $30(56.6 \%)$ \\
\hline Patients with node positive disease & & $47(88.7 \%)$ \\
\hline Patients with grade 3 disease & & $31(58.5 \%)$ \\
\hline Patients who have had, or were offered chemotherapy & & $47(88.7 \%)$ \\
\hline Premenopausal patients receiving GnRH agonist for ovarian function suppression & & $28(52.8 \%)$ \\
\hline Patients with any stage of lobular breast cancer & & $3(5.7 \%)$ \\
\hline Triple negative breast cancer & & $28(52.8 \%)$ \\
\hline HER 2 positive breast cancer & & $22(41.5 \%)$ \\
\hline Patients with high Oncotype DX score & & $39(73.6 \%)$ \\
\hline Other & & $1(1.9 \%)$ \\
\hline 10-year risk of recurrence for consideration of adjuvant bone-targeted agent & 53 & \\
\hline All patients should be considered & & $2(3.8 \%)$ \\
\hline 10 -year disease recurrence risk $>5 \%$ & & $7(13.2 \%)$ \\
\hline 10 -year disease recurrence risk $>10 \%$ & & $25(47.2 \%)$ \\
\hline 10 -year disease recurrence risk $>12 \%$ & & $9(17.0 \%)$ \\
\hline 10 -year disease recurrence risk $>20 \%$ & & $10(18.8 \%)$ \\
\hline Other, please state & & $0(0 \%)$ \\
\hline 10 -year risk of mortality for consideration of adjuvant bone-target agent & 35 & \\
\hline All patients should be considered & & $1(2.8 \%)$ \\
\hline 10 -year breast cancer mortality rate $>5 \%$ & & $17(48.6 \%)$ \\
\hline 10 -year breast cancer mortality rate $>10 \%$ & & $11(31.4 \%)$ \\
\hline 10 -year breast cancer mortality rate $>12 \%$ & & $5(14.3 \%)$ \\
\hline 10 -year breast cancer mortality rate $>20 \%$ & & $1(\%)$ \\
\hline Other, please state & & $0(0 \%)$ \\
\hline Which receptor status benefits most from adjuvant bisphosphonates, (multiple selections possible) & 53 & \\
\hline Triple negative & & $6(11.3 \%)$ \\
\hline HER 2 positive & & $4(7.5 \%)$ \\
\hline ER/PR positive & & $25(47.2 \%)$ \\
\hline All of the above & & $23(43.4 \%)$ \\
\hline How consistently do you offer adjuvant bisphosphonate therapy to high risk patients (whichever "high risk" is defined) & 53 & \\
\hline Always & & $14(26.4 \%)$ \\
\hline Frequently ( $>75 \%$ of the time) & & $27(50.9 \%)$ \\
\hline Sometimes (50-75\% of the time) & & $4(7.5 \%)$ \\
\hline Occasionally $(<10 \%$ of the time $)$ & & $4(7.5 \%)$ \\
\hline Rarely $(<10 \%$ of the time $)$ & & $2(3.8 \%)$ \\
\hline Never & & $2(3.8 \%)$ \\
\hline Which of the following bone modifying agents do you prefer to use for adjuvant therapy & 53 & \\
\hline Zoledronic Acid & & $47(88.7 \%)$ \\
\hline Clodronate & & $0(0 \%)$ \\
\hline Denosumab & & $1(1.9 \%)$ \\
\hline I don't have a preference & & $4(7.5 \%)$ \\
\hline
\end{tabular}


Table 2 (continued)

\begin{tabular}{|c|c|c|}
\hline & $N$ & $N(\%)$ \\
\hline Other bisphosphonates, please specify: & & $1(1.9 \%)$ \\
\hline I don't use & & 1 \\
\hline Preference of dose and duration of adjuvant zoledronate & 53 & \\
\hline Zoledronate $4 \mathrm{mg}$ IV every $3-4$ weeks $\mathrm{x} 6$, then 3 monthly $\mathrm{x} 8$, then 6 monthly $\mathrm{x} 5$ for 5 years & & $0(0 \%)$ \\
\hline Every 6 months for 5 years & & $4(7.5 \%)$ \\
\hline Every 6 months for 3 years & & $45(84.9 \%)$ \\
\hline I don't prescribe zoledronate & & $2(3.8 \%)$ \\
\hline Other & & $2(3.8 \%)$ \\
\hline Every 6 months for 2.5 years & & 1 \\
\hline Every 3 months for 2 years & & 1 \\
\hline Barriers to the wider use of adjuvant bisphosphonate (multiple selections possible) & 53 & \\
\hline Risk of toxicities on treatment (e.g. renal toxicity, ONJ, atypical fractures) & & $34(64.2 \%)$ \\
\hline Reduced patient quality of life on treatment & & $9(17.0 \%)$ \\
\hline Increased cost of patient care (e.g. chair time for intravenous treatments) & & $14(26.4 \%)$ \\
\hline Treatment, and follow up, at the cancer centre are prolonged & & $28(52.8 \%)$ \\
\hline I do not feel the breast cancer benefits are clinically meaningful & & $5(9.4 \%)$ \\
\hline Other & & $5(9.4 \%)$ \\
\hline I think they are overused at this time & & 1 \\
\hline Small incremental benefits, now can use extended adjuvant endocrine & & 1 \\
\hline Some patients refuse to tolerate immediate side effects & & 1 \\
\hline Access & & 1 \\
\hline In Quebec Zoledronate treatment is not approved for adjuvant breast cancer treatment, difficult access & & 1 \\
\hline
\end{tabular}

ONJ osteonecrosis of the jaw

\section{Discussion}

Evidence-based guideline groups have recommended bisphosphonates as adjuvant therapy for postmenopausal women with EBC as well as premenopausal women treated with ovarian suppression [2, 9-12]. However, the optimal choice, dosage and duration of bisphosphonate treatment for preventing recurrence and improving survival in women with EBC is unclear. Two important challenges still remain for patients and health care providers, the first being how to increase the number of patients being offered this treatment. The second challenge is identifying the optimum schedule, duration, and type of bisphosphonate therapy. This survey was devised to gain an understanding of current prescribing patterns of Canadian physicians of BMA and provide guidance for potential future trial designs. The latter is of particular importance given that trials in metastatic disease [13-21], AI-induced bone loss [22], and osteoporosis [23-26], have all demonstrated efficacy with less frequent administration of BMAs.

Survey respondents came from across Canada with varying durations in clinical practice, from early to late career. All physicians were aware of clinical practice guidelines recommending the use of adjuvant bisphosphonate therapy in patients with EBC and not surprisingly the most commonly cited was the $\mathrm{CCO} / \mathrm{ASCO}$ guideline. Most respondents were aware that these guidelines recommend adjuvant bisphosphonate use for postmenopausal patients with high risk disease. Most physicians cited that the EBCTCG meta-analyses of adjuvant bisphosphate use reported benefit in terms of; reduced risk of disease recurrences/relapse in the bone, increased overall survival and increased breast cancer specific survival.

In their own clinical practice, most respondents recommend BMA use for postmenopausal patients with high risk disease and the most commonly used regimen was 6-monthly zoledronate for 3 years. Interestingly, no respondents were using adjuvant clodronate. This was despite the SWOG 0307 trial that compared intravenous zoledronic acid, oral clodronate, or oral ibandronate, showing no evidence of differences in efficacy by type of bisphosphonate. Indeed, in this study patients expressed preference for oral formulation [27]. Clodronate is not approved for this indication in the USA, while in Canada Respondents felt the greatest barriers to the wider use of adjuvant bisphosphonate therapy were; overall survival, risk of toxicities on treatment (e.g. renal toxicity, ONJ, atypical fractures), and increased requirement for follow up and treatment at the cancer centre.

However, despite the recommendations of evidencebased guideline groups and the findings of the survey it 
Table 3 Interest in adjuvant bone-modifying agent de-escalation studies

\begin{tabular}{|c|c|c|}
\hline & $N$ & $N(\%)$ \\
\hline Would you enroll a patient on a study looking at fewer adjuvant bisphosphonates treatments? & 53 & \\
\hline Yes & & $45(84.9 \%)$ \\
\hline No & & $0(0 \%)$ \\
\hline Maybe & & $8(15.1 \%)$ \\
\hline Choice of first most important study endpoint: & 53 & \\
\hline Incidence of loco-regional breast cancer recurrence & & $0(0 \%)$ \\
\hline Incidence of breast cancer recurrence at any site including loco-regional & & $9(17.0 \%)$ \\
\hline Incidence of bone metastasis recurrence & & $8(15.1 \%)$ \\
\hline Incidence of fragility (osteoporotic) fractures & & $0(0 \%)$ \\
\hline $\begin{array}{l}\text { Combination of the incidence of breast cancer recurrence at any site including loco-regional as well as the inci- } \\
\text { dence of fragility fractures }\end{array}$ & & $14(26.4 \%)$ \\
\hline Combination of the incidence of bone metastasis recurrence as well as the incidence of fragility fractures & & $14(26.4 \%)$ \\
\hline Effects on bone mineral density & & $0(0 \%)$ \\
\hline Overall survival & & $8(15.1 \%)$ \\
\hline Toxicities & & $0(0 \%)$ \\
\hline Quality of life & & $0(0 \%)$ \\
\hline Cost effectiveness & & $0(0 \%)$ \\
\hline Other & & $0(0 \%)$ \\
\hline Second most important clinical endpoint: & 53 & \\
\hline Incidence of loco-regional breast cancer recurrence & & $7(13.2 \%)$ \\
\hline Incidence of breast cancer recurrence at any site including loco-regional & & $0(0 \%)$ \\
\hline Incidence of bone metastasis recurrence & & $7(13.2 \%)$ \\
\hline Incidence of fragility (osteoporotic) fractures & & $2(3.8 \%)$ \\
\hline Combination of the incidence of breast cancer recurrence at any site including loco-regional as well as the & & $7(13.2 \%)$ \\
\hline Incidence of fragility fractures & & $2(3.8 \%)$ \\
\hline Combination of the incidence of bone metastasis recurrence as well as the incidence of fragility fractures & & $3(5.7 \%)$ \\
\hline Effects on bone mineral density & & $12(22.6 \%)$ \\
\hline Overall survival & & $7(13.2 \%)$ \\
\hline Toxicities & & $3(5.7 \%)$ \\
\hline Quality of life & & $3(5.7 \%)$ \\
\hline Cost effectiveness & & $0(0 \%)$ \\
\hline \multicolumn{3}{|l|}{ Other } \\
\hline If such a trial were designed, what design would you prefer (choices ranked): & 53 & \\
\hline Single infusion of zoledronate vs. zoledronate every 6 months for 3 years & & $44(83.0 \%)$ \\
\hline Single infusion of zoledronate vs. zoledronate every 6 months for 5 years & & $28(52.8 \%)$ \\
\hline Oral coldronate vs. zoledronate every 6 months for 3 years & & $26(49 \%)$ \\
\hline
\end{tabular}

is evident that many questions remain around the optimal choice of agent, route of administration, dose and dosing schedule [28]. This is important as the EBCCTG metaanalysis [1] was unable to demonstrate the superiority of longer durations of bisphosphonate use over shorter schedules. Indeed, this inability to identify the optimal agent, dose or duration of therapy is particularly important with zoledronate where the trials included different durations, dosing intervals, and total number of infusions [9, 29, 30]. Despite different numbers of zoledronate doses at $4 \mathrm{mg}$ with 11 doses in ZO-FAST, 19 doses in AZURE and 7 doses in ABCSG-12 the hazard ratio for disease-free interval was similar (between 0.66 and 0.77 ) in these trials [9, 29, 30]. The SUCCESS trial compared 2 years of adjuvant zoledronate with 5 years of therapy, and while making no difference in the primary endpoint of bone metastasis free survival, the extra 3 years was associated with a significantly higher incidence of renal toxicity and osteonecrosis of the jaw [31]. Given all these findings it is not surprising that most physicians recommend 6-monthly zoledronate over 3 years over more intense zoledronate regimens for their patients. However, questions around why oral clodronate was not recommended by the respondents require further exploration. 
The CCO/ASCO Practice Guideline, 'Bottom line recommendations' specifically states, "More research is recommended comparing different bone-modifying agents, doses, dosing intervals, and durations" [2]. For this reason, it is not surprising that most $(39$ (83.0\%) physicians in our survey were interested in enrolling patients on trials using fewer bisphosphonate infusions. The most frequently selected trial design was for a randomised trial comparing a single injection of zoledronate with 6 -monthly treatment for 3 years. While a single infusion may be viewed as under treatment, studies have evaluated single-dose of zoledronate and the resulting increase in bone density over 2 years [25, 26], 3 years [32] and 5 years [22] in different patient populations including those with cancer.

Respondents felt the most important primary endpoint for de-escalation trials should be: a combination of the incidence of bone metastasis recurrence as well as the incidence of fragility fractures; a combination of the incidence of breast cancer recurrence at any site including loco-regional as well as the incidence of fragility fractures; or the incidence of breast cancer recurrence at any site including loco-regional. The most important secondary endpoints identified were overall survival, treatmentrelated toxicities or the incidence of bone metastasis recurrence. Challenges of study designs using endpoints such as fragility fractures and bone recurrences however would be the requirement for a large sample size of several thousand patients, and follow up of several years [9, 10, 29].

There are clear limitations to this study. Firstly, there is always an inherent selection bias in those that are contacted and in those that respond to surveys. In addition, while the study team endeavor to keep our list of email addresses for health care providers up to date this is not always possible. This may explain while although respondents here reported prescribing BMAs to the majority of eligible patients, data shows that only around $20 \%$ of eligible patients in Ontario receive adjuvant bisphosphonates. As this is a survey of Canadian health care providers, the choice of BMA is influenced by the funding structure for different agents. In Ontario, adjuvant zoledronate has been publicly funded since 2015, whereas in Quebec the physician has to apply for funding on a case by case basis. Another challenge for this survey was the response rate. As we have observed, the overwhelming situation to all health care workers during the COVID19 pandemic has made the performance of surveys, and clinical research overall, very challenging. However, despite this, the quality of data received by respondents was excellent, as evidenced by many who took the time to inform us of alternative trial designs shown in Table 3.

\section{Conclusions}

To date there has been limited adoption of 6-monthly zoledronate for 3 years as adjuvant therapy for postmenopausal women with higher risk breast cancer in many parts of Canada with the greatest barriers to more widespread use being the risk of treatment-induced toxicities and the increased requirement for follow up and treatment at the cancer centre. Physicians still have questions around the optimal scheduling of zoledronate and are enthusiastic about enrolling patients in a possible trial of single agent zoledronate vs 6 -monthly treatment. Health care providers are however, less enthusiastic about trials using either clodronate or longer durations of zoledronate. Given the endpoints identified as important to physicians, such a trial will clearly require a large sample size and considerable international collaboration.

Supplementary Information The online version contains supplementary material available at https://doi.org/10.1007/s10549-021-06147-1.

Acknowledgements We are grateful to health care providers for their participation in this survey.

Author contributions SM, AJM, LV, KC, GL, GP and MC designed the survey and prepared the protocol. LV collected the data and coordinated the study. SM, AJM, and GP did the statistical analysis. All authors had full access to the data and take responsibility for the integrity of the data and the accuracy of the data analysis. SM, AJM, GP, DS and $\mathrm{MC}$ wrote the manuscript. All authors were involved in the critical review of the manuscript and approved the final version.

Funding The research did not receive any specific grant from funding agencies in the public, commercial, or not-for-profit sectors. This work was supported by the Rethinking Clinical Trials (REaCT) Program platform at the Ottawa Hospital which is supported by The Ottawa Hospital Foundation and its generous donors.

Data availability Anonymized dataset is available upon request and approval by the Ontario Cancer Research Ethics Board.

\section{Declarations}

Conflict of interest SMG reports receipt of honorarium from Novartis for insights on management of breast cancer patients. AA has participated on an advisory board for Novartis, Eli Lily, Exactis innovation and Pfizer, has received honoraria from Apobiologix and Roche and has received travel funds from Roche. $\mathrm{BH}$ and $\mathrm{MC}$ reports consulting fees from Cornerstone Research, outside the submitted work. All other authors declare no competing interests.

Ethical approval All procedures performed in studies involving human participants were in accordance with the ethical standards of each institution Research Ethics Board and with the 1964 Helsinki declaration and its later amendments or comparable ethical standards. All data has been anonymized to protect the identities of subjects involved in the research.

Informed consent Completion of the survey implied consent to participate. 


\section{References}

1. Early Breast Cancer Trialists' Collaborative Group (2015) Adjuvant bisphosphonate treatment in early breast cancer: meta-analyses of individual patient data from randomised trials. Lancet 386(10001):1353-1361

2. Dhesy-Thind S, Fletcher GG, Blanchette PS, Clemons MJ, Dillmon MS, Frank ES, Gandhi S, Gupta R, Mates M, Moy B, Vandenberg T, Van Poznak CH (2017) Use of adjuvant bisphosphonates and other bone-modifying agents in breast cancer: a cancer care ontario and american society of clinical oncology clinical practice guideline. J Clin Oncol 35(18):2062-2081

3. Hadji P, Coleman RE, Wilson C, Powles T, Clézardin P, Aapro M, Costa L, Body J-J, Markopoulos C, Santini D (2016) Adjuvant bisphosphonates in early breast cancer: consensus guidance for clinical practice from a European Panel. Ann Oncol 27(3):379-390

4. Balic M, Thomssen C, Würstlein R, Gnant M, Harbeck N (2019) St. Gallen/Vienna 2019: a brief summary of the consensus discussion on the optimal primary breast cancer treatment. Breast Care 14(2):103-110

5. Curigliano G, Burstein HJ, Winer EP, Gnant M, Dubsky P, Loibl S, Colleoni M, Regan MM, Piccart-Gebhart M, Senn H-J (2017) De-escalating and escalating treatments for early-stage breast cancer: the St Gallen International Expert Consensus Conference on the Primary Therapy of Early Breast Cancer 2017. Ann Oncol 28(8):1700-1712

6. Cancer Care Ontario, Data request to the Cancer Care Ontario Disclousre Team (2020) https://www.ccohealth.ca/en/requestdata-for-research. (Accessed April 14 2020)

7. McGee SF, Vandermeer L, Mazzarello S, Sienkiewicz M, Stober C, Hutton B, Fergusson D, Hilton J, Caudrelier J-M, Blanchette $P$ (2019) Physician survey of timing of adjuvant endocrine therapy relative to radiotherapy in early stage breast cancer patients. Clin Breast Cancer 19(1):e40-e47

8. Coleman R, Finkelstein DM, Barrios C, Martin M, Iwata H, Hegg R, Glaspy J, Periañez AM, Tonkin K, Deleu I (2020) Adjuvant denosumab in early breast cancer (D-CARE): an international, multicentre, randomised, controlled, phase 3 trial. Lancet Oncol 21(1):60-72

9. Coleman R, de Boer R, Eidtmann H, Llombart A, Davidson N, Neven P, von Minckwitz G, Sleeboom HP, Forbes J, Barrios C, Frassoldati A, Campbell I, Paija O, Martin N, Modi A, Bundred N (2013) Zoledronic acid (zoledronate) for postmenopausal women with early breast cancer receiving adjuvant letrozole (ZO-FAST study): final 60-month results. Ann Oncol 24(2):398-405

10. Gnant M, Pfeiler G, Dubsky PC, Hubalek M, Greil R, Jakesz R, Wette V, Balic M, Haslbauer F, Melbinger E, Bjelic-Radisic V, Artner-Matuschek S, Fitzal F, Marth C, Sevelda P, Mlineritsch B, Steger GG, Manfreda D, Exner R, Egle D, Bergh J, Kainberger F, Talbot S, Warner D, Fesl C, Singer CF (2015) Adjuvant denosumab in breast cancer (ABCSG-18): a multicentre, randomised, double-blind, placebo-controlled trial. Lancet (London, England) 386(9992):433-43

11. Ellis GK, Bone HG, Chlebowski R, Paul D, Spadafora S, Smith J, Fan M, Jun S (2008) Randomized trial of denosumab in patients receiving adjuvant aromatase inhibitors for nonmetastatic breast cancer. J Clin Oncol 26(30):4875-82

12. Coleman R, Body JJ, Aapro M, Hadji P, Herrstedt J (2014) Bone health in cancer patients: ESMO Clinical Practice Guidelines. Ann Oncol 25(Suppl 3): iii124-37

13. Amir E, Freedman O, Carlsson L, Dranitsaris G, Tomlinson G, Laupacis A, Tannock IF, Clemons M (2013) Randomized feasibility study of de-escalated (every $12 \mathrm{wk}$ ) versus standard (every 3 to $4 \mathrm{wk}$ ) intravenous pamidronate in women with low-risk bone metastases from breast cancer. Am J Clin Oncol 36(5):436-42

14. Kuchuk I, Beaumont JL, Clemons M, Amir E, Addison CL, Cella D (2013) Effects of de-escalated bisphosphonate therapy on the Functional Assessment of Cancer Therapy-Bone Pain, Brief Pain Inventory and bone biomarkers. J Bone Oncol 2(4):154-7

15. Addison CL, Pond GR, Zhao H, Mazzarello S, Vandermeer L, Goldstein R, Amir E, Clemons M (2014) Effects of de-escalated bisphosphonate therapy on bone turnover biomarkers in breast cancer patients with bone metastases. Springerplus 3:577

16. Addison CL, Bouganim N, Hilton J, Vandermeer L, Dent S, Amir E, Hopkins S, Kuchuk I, Segal R, Song X, Gertler S, Mazzarello S, Dranitsaris G, Ooi D, Pond G, Clemons M (2014) A phase II, multicentre trial evaluating the efficacy of de-escalated bisphosphonate therapy in metastatic breast cancer patients at low-risk of skeletal-related events. Breast Cancer Res Treat 144(3):615-24

17. Amadori D, Aglietta M, Alessi B, Gianni L, Ibrahim T, Farina G, Gaion F, Bertoldo F, Santini D, Rondena R, Bogani P, Ripamonti CI (2013) Efficacy and safety of 12-weekly versus 4-weekly zoledronic acid for prolonged treatment of patients with bone metastases from breast cancer (ZOOM): a phase 3, open-label, randomised, non-inferiority trial. Lancet Oncol 14(7):663-70

18. Lipton A, Steger GG, Figueroa J, Alvarado C, Solal-Celigny P, Body JJ, de Boer R, Berardi R, Gascon P, Tonkin KS, Coleman R, Paterson AH, Peterson MC, Fan M, Kinsey A, Jun S (2007) Randomized active-controlled phase II study of denosumab efficacy and safety in patients with breast cancer-related bone metastases. J Clin Oncol 25(28):4431-7

19. Himelstein AL, Foster JC, Khatcheressian JL, Roberts JD, Seisler DK, Novotny PJ, Qin R, Go RS, Grubbs SS, O'Connor T, Velasco MR Jr, Weckstein D, O’Mara A, Loprinzi CL, Shapiro CL (2017) Effect of longer-interval vs standard dosing of zoledronic acid on skeletal events in patients with bone metastases: a randomized clinical trial. JAMA 317(1):48-58

20. Hortobagyi GN, Van Poznak C, Harker WG, Gradishar WJ, Chew H, Dakhil SR, Haley BB, Sauter N, Mohanlal R, Zheng M, Lipton A (2017) Continued treatment effect of zoledronic acid dosing every 12 vs 4 weeks in women with breast cancer metastatic to bone: the OPTIMIZE-2 randomized clinical trial. JAMA Oncol 3(7):906-912

21. Ibrahim MF, Mazzarello S, Shorr R, Vandermeer L, Jacobs C, Hilton J, Hutton B, Clemons M (2015) Should de-escalation of bone-targeting agents be standard of care for patients with bone metastases from breast cancer? Ann Oncol 26(11):2205-13

22. Brown JE, Ellis SP, Lester JE, Gutcher S, Khanna T, Purohit OP, McCloskey E, Coleman RE (2007) Prolonged efficacy of a single dose of the bisphosphonate zoledronic acid. Clin Cancer Res 18(Pt 1):5406-10

23. Khan SA, Kanis JA, Vasikaran S, Kline WF, Matuszewski BK, McCloskey EV, Beneton MN, Gertz BJ, Sciberras DG, Holland SD, Orgee J, Coombes GM, Rogers SR, Porras AG (1997) Elimination and biochemical responses to intravenous alendronate in postmenopausal osteoporosis. J Bone Miner Res 12(10):1700-7

24. Black DM, Delmas PD, Eastell R, Reid IR, Boonen S, Cauley JA, Cosman F, Lakatos P, Leung PC, Man Z, Mautalen C, Mesenbrink P, Hu H, Caminis J, Tong K, Rosario-Jansen T, Krasnow J, Hue TF, Sellmeyer D, Eriksen EF, Cummings SR (2007) Once-yearly zoledronic acid for treatment of postmenopausal osteoporosis. $\mathrm{N}$ Engl J Med 356(18):1809-22

25. Greenspan SL, Perera S, Ferchak MA, Nace DA, Resnick NM (2015) Efficacy and safety of single-dose zoledronic acid for osteoporosis in frail elderly women: a randomized clinical trial. JAMA Internal Med 175(6):913-21

26. Ofotokun I, Titanji K, Lahiri CD, Vunnava A, Foster A, Sanford SE, Sheth AN, Lennox JL, Knezevic A, Ward L, Easley KA, 
Powers P, Weitzmann MN (2016) A Single-Dose Zoledronic Acid Infusion Prevents Antiretroviral Therapy-Induced Bone Loss In Treatment-naive HIV-infected patients: a phase IIb trial. Clin Infect Dis 63(5):663-671

27. Gralow JR, Barlow WE, Paterson AH, Miao JL, Lew DL, Stopeck AT, Hayes DF, Hershman DL, Schubert MM, Clemons M (2020) Phase III randomized trial of bisphosphonates as adjuvant therapy in breast cancer: S0307. J Natl Cancer Inst

28. Jacobs C, Amir E, Paterson A, Zhu X, Clemons M (2015) Are adjuvant bisphosphonates now standard of care of women with early stage breast cancer? A debate from the Canadian Bone and the Oncologist New Updates meeting. J Bone Oncol 4(2):54-8

29. Coleman R, Cameron D, Dodwell D, Bell R, Wilson C, Rathbone E, Keane M, Gil M, Burkinshaw R, Grieve R, Barrett-Lee P, Ritchie D, Liversedge V, Hinsley S, Marshall H (2014) Adjuvant zoledronic acid in patients with early breast cancer: final efficacy analysis of the AZURE (BIG 01/04) randomised open-label phase 3 trial. Lancet Oncol 15(9):997-1006

30. Gnant M, Mlineritsch B, Stoeger H, Luschin-Ebengreuth G, Knauer M, Moik M, Jakesz R, Seifert M, Taucher S, Bjelic-Radisic V, Balic M, Eidtmann H, Eiermann W, Steger G, Kwasny W,
Dubsky P, Selim U, Fitzal F, Hochreiner G, Wette V, Sevelda P, Ploner F, Bartsch R, Fesl C, Greil R (2015) Zoledronic acid combined with adjuvant endocrine therapy of tamoxifen versus anastrozol plus ovarian function suppression in premenopausal early breast cancer: final analysis of the Austrian Breast and Colorectal Cancer Study Group Trial 12. Ann Oncol 26(2):313-20

31. Domschke C, Schuetz F (2014) Side effects of bone-targeted therapies in advanced breast cancer. Breast Care (Basel, Switzerland) 9(5):332-6

32. Grey A, Bolland MJ, Horne A, Mihov B, Gamble G, Reid IR (2017) Duration of antiresorptive activity of zoledronate in postmenopausal women with osteopenia: a randomized, controlled multidose trial. CMAJ Can Med Assoc J [Journal de l'Association medicale canadienne] 189(36): E1130-E1136

Publisher's Note Springer Nature remains neutral with regard to jurisdictional claims in published maps and institutional affiliations. 